\title{
Short communication: Expression of IL-23 in gilt endometrium and oviduct after insemination with seminal plasma, spermatozoa or semen extender
}

\section{Anna Svensson ( $\square$ anna.svensson@slu.se )}

Sveriges Lantbruksuniversitet Veterinarmedicin och husdjursvetenskap https://orcid.org/0000-00034015-2001

Jatesada Jiwakanon

Khon Kaen University

Caroline Fossum

Sveriges lantbruksuniversitet

Anne-Marie Dalin

Sveriges lantbruksuniversitet

Research article

Keywords: IL-23, mRNA expression, Gilt, Endometrium, Oviduct, Insemination, PMN

Posted Date: December 17th, 2020

DOl: https://doi.org/10.21203/rs.3.rs-41381/v2

License: (9) This work is licensed under a Creative Commons Attribution 4.0 International License.

Read Full License 


\section{Abstract}

Background: Insemination with spermatozoa, seminal plasma and extender, cause a rapid inflammatory response in the pig endometrium, which is characterized by an influx of neutrophils into the uterus. The transient inflammatory response to semen involves induction of cytokines. In this study, potential functions for Interleukin-23 (IL-23) in the inflammatory response to different insemination treatments were examined by studying mRNA expression and immunostaining in gilt oviduct and endometrium 35$40 \mathrm{~h}$ after insemination. Insemination was performed with either seminal plasma (SP, $n=4)$, spermatozoa in the extender Beltsville thawing solution (BTS) $(S P Z, n=4)$, or BTS alone $(n=4)$. In control gilts $(n=4)$ an insemination catheter was inserted without anything being inseminated.

Results: Results showed that IL-23 mRNA was expressed in the oviduct and in the endometrium. There was an approximate 2-4-fold increase in expression of IL-23 mRNA in catheter-only control compared with SPZ, SP and BTS treatment groups. IL-23 immunolabelling was detected in a small number of separate cells as well as in the sub-epithelial connective tissue of the endometrium, the endosalpinx of the isthmus and infundibulum.

Conclusions: All fluids used for insemination decreased the expression of IL-23 mRNA in the endometrium compared to catheter-insertion alone, indicating a possible role for IL-23 in the inflammatory response after insemination in gilts.

\section{Background}

Insemination with spermatozoa, seminal plasma (SP) and extender inserted into the uterus via a catheter, causes a rapid inflammatory response in the pig endometrium, which is characterized by an influx of neutrophils into the uterine lumen $[1,10,19]$. Neutrophils are present in the surface epithelium and subepithelial layer of the endometrium until approximately $40 \mathrm{~h}$ after insemination [10]. The increase in neutrophil number in the pig uterus after insemination has been suggested to be due to chemotactic signals elicited by the insemination procedure $[12,19]$. Notably, the influx of neutrophils into the uterine lumen was more pronounced when the insemination was performed with semen than with extender alone [19]. In pig oviduct, neutrophils are absent in the isthmic part of the oviduct but present in the connective tissue of the infundibulum about $40 \mathrm{~h}$ after insemination with fresh semen in the extender BTS (Beltsville Thawing Solution) [5].

The transient inflammatory response to semen in the pig reproductive tract involves induction of cytokines and chemokines [18]. Our previous immunohistochemical studies demonstrated presence of IL6, IL-10 and TGF- $\beta 1$ in gilt oviduct (isthmus and infundibulum) [6] and in the endometrium [7] at 5-6 $\mathrm{h}$ and 35-40 $\mathrm{h}$ after insemination with different components (SP, spermatozoa in BTS or BTS). Staining was primarily seen in the epithelium of both the oviduct [6] and the endometrium [7]. Comparison of mRNA expression for IL-1 $\beta$, IL-6, IL-10, TGF- $\beta 1$ and GM-CSF after insemination with SP, spermatozoa in BTS or BTS revealed no difference in the endometrium shortly (5-6 h) after insemination [7]. However, at 35-40 $\mathrm{h}$ 
after insemination, TGF- $\beta 1$ mRNA expression was lower in samples obtained from gilts inseminated with BTS or with spermatozoa in BTS compared with catheter-insertion controls. No difference between treatment groups was observed regarding the GM-CSF mRNA expression [7], which was in agreement with results from Taylor et al [20] but in contrast to results obtained by O'Leary et al [15], who found SP to induce GM-CSF mRNA expression $34 \mathrm{~h}$ after insemination. Hence, studies of the expression of proinflammatory and suppressive cytokines in the porcine reproductive tract indicate complex patterns in the response to insemination that seems to be influenced by the components included, i.e., SP, spermatozoa and/or extender. Therefore, archived samples from our previous studies [6,7] were further analyzed for the expression IL-23. This cytokine promotes differentiation and proliferation of Th17 cells $[13,16]$. Th17 cells are implicated in inflammation by stimulating a variety of cells to produce cytokines but also by promoting chemokine production, with subsequent recruitment of neutrophils [13]. In human IL-23 regulates the function of decidual immune cells [2]. Weak IL-23 p19 immunolabelling has been detected in human endometrium [21] and IL-23 expression has been shown to increase in decidual tissue from patients with unexplained recurrent spontaneous abortion compared to controls [3].

The aim of the present study was to investigate the potential role for IL-23 in the inflammatory response to insemination by studying mRNA expression and immunostaining in gilt oviduct and endometrium 35$40 \mathrm{~h}$ after insemination with either SP or spermatozoa in the extender BTS, or BTS alone, and compare to that induced by insertion of catheter only in control gilts.

\section{Results}

\section{IL-23 expression}

Quantitative real-time PCR experiments showed IL-23 mRNA to be expressed in gilt oviduct (isthmus and infundibulum) and endometrium 35-40 h after insemination regardless of treatment (Fig. 1). The results indicated a difference in expression between individual animals, which was independent of treatment and tissue.

Statistical analysis of fixed effects showed significant differences $(p<0.01)$ in IL-23 mRNA expression due to treatment. When all tissues within a treatment group were analyzed together, the SPZ in BTS, SP and BTS treatment groups differed significantly $(p<0.05)$ from the catheter group but not from each other (NS), regarding IL-23 mRNA expression. The significant interaction $(p \leq 0.05)$ between tissue and treatment is shown in Fig. 1. Endometrium from the catheter-insertion control gilts exhibited the highest IL-23 mRNA expression of all tissues examined. The effect of treatment was more pronounced in the endometrium than in the isthmus and infundibulum of the oviduct.

Immunohistochemical labelling indicated the presence of IL-23 in the endometrium as well as in the endosalpinx of the isthmus and infundibulum. The staining was mainly found in the cytoplasm of the sub-epithelial connective tissue cells of the endometrium (Fig. 2A, B) and the same localization of staining was observed in the oviduct (isthmus and infundibulum; results not shown). No obvious epithelial (surface or glandular) staining was observed in any of the tissues examined (endometrium; Fig. 
2). Sections incubated with control IgG (endometrium; Fig. 2C) or with secondary antibodies only did not give any staining, regardless of tissue or treatment.

Distinct IL-23 immunolabelled cells were found in both oviduct (results not shown) and endometrium (Fig. 3). Although the cells displaying IL-23 immunostaining were not numerous, they were present in all treatment groups. No observable staining of individual cells was found with the control rabbit IgG. IL-23 immunolabelling intensity scores differed between individual gilts, however no significant differences were found between treatments or tissues (results not shown).

\section{Endometrial PMNs}

Results from the quantification of PMNs in the endometrium have previously been reported by Jiwakanon et al. [7] and are shown here in Fig. 4. There were lower numbers of PMNs present per unit area in the surface epithelium than in the sub-epithelial connective tissue. The PMN number in the sub-epithelial connective tissue was significantly different between the SP and the catheter-insertion group at 35-40 h after insemination ( $p<0.05$; Fig. 4).

\section{Discussion}

IL-23 has earlier been studied in human endometrium but to our knowledge, not in pig reproductive organs. The present study showed IL-23 mRNA to be expressed in the oviduct and endometrium in gilts 35-40 $\mathrm{h}$ after insemination and in all treatment groups. The time point chosen for sampling, $35-40 \mathrm{~h}$ after insemination, is estimated to $20-25 \mathrm{~h}$ after ovulation, based on our earlier studies using the same time of insemination with subsequent ultrasound monitoring to check for ovulation [10]. Furthermore, our earlier studies $[6,7]$ revealed more clear treatment-dependent changes in cytokine mRNA expression at 35-40 $\mathrm{h}$ than shortly (5-6 h) after insemination. In addition, in gilts/sows inseminated with fresh semen, fertilized oocytes are then to be found in the oviduct [9]. In the uterus, the acute inflammatory reaction in the endometrium should decline to prepare for the entrance of early embryos [10]. Previous studies in gilts $[6,7]$ showed pro-inflammatory cytokine mRNAs to be differentially expressed at 35-40 $\mathrm{h}$ compared to shortly (5-6 h) after insemination. In the present study, the IL-23 p19 mRNA expression varied between gilts, regardless of treatment or tissue. The previous studies of mRNA expression for IL-10, IL-6 and TGF- $\beta$ in the same animals, also showed a high variation in the endometrium [7] but not in the oviduct [6].

There was a significantly lower expression of IL-23 mRNA in the SPZ, SP and BTS treatment groups, compared with the catheter-insertion group, but no significant differences in expression between any of the three insemination groups. The endometrium from catheter-insertion gilts exhibited the highest IL-23 mRNA expression of all tissues examined. The effect of treatment was more pronounced in the endometrium than in the isthmus or infundibulum of the oviduct. Since the highest expression was seen in the catheter-insertion group, a suggestion is that components in the SPZ, SP and BTS treatments may exert some kind of suppression on IL-23 mRNA expression. To determine specific suppressive effects of each treatment (SPZ, SP, BTS), additional animals inseminated with an equal volume of $0.9 \% \mathrm{NaCl}$ would be of interest. 
IL-23 promotes differentiation and proliferation of Th17 cells $[13,16]$ that are involved in inflammation by stimulating cytokine and chemokine production by a variety of cells, with subsequent recruitment of neutrophils $[2,11,16]$. Increased levels of IL-23/IL-17 may be crucial for the diapedesis of neutrophils into tissues in pigs [11]. A role for IL-23 in recruitment of neutrophils would be a possibility in gilt endometrium as seen after catheter insertion. As shown in gilts of the present study [7; Fig. 4, present paper] and in another study [9], neutrophils migrate into the endometrium in gilts inseminated with spermatozoa, whereas SP suppresses neutrophilic invasion and inflammation in the endometrium. The higher IL-23 mRNA expression in endometrium of control group coincides in time (35-40 h) after treatment with a significantly higher presence of neutrophils compared with the SP group (in the subepithelial connective tissue), indicating that SP may not only limit the neutrophil influx but also limit the expression of IL-23. No significant differences in IL-23 mRNA expression were obtained between the different parts of the oviduct, which might have been expected, since no neutrophils are found in isthmus after insemination [5]. However, more studies are needed to draw any conclusions about possible roles for IL-23 and neutrophil presence in porcine reproductive tissue.

Weak IL-23 p19 immunostaining has been shown in the cytoplasm of the sub-epithelial connective tissue cells of the human endometrium [21]. In the present study, both weak cytoplasm staining and low numbers of distinct IL-23 immunolabelled cells were found in both oviduct (endosalpinx of isthmus and infundibulum) and endometrium. These distinctly stained immune cells were, however, too few for any conclusion to be drawn regarding impact of treatment on immunolabelled cell numbers. Although the cells displaying distinct IL-23 immunolabelling were not numerous, they were present in all treatment groups. No obvious staining of IL-23 was observed in the surface or glandular epithelium in any of the tissues examined. The pattern of IL-23 is in part similar with the results of previous immunohistochemical labelling of TGF- $\beta 1$ in endometrial tissue showing significantly higher expression for catheter than for BTS and SPZ but no difference compared with SP [7]. In addition, no difference between the groups was found for IL-10. For the pro-inflammatory IL-6, the expression was low in all groups but the catheter resulted in significantly lower expression than BTS [7]. SP from boar has been shown to contain the suppressive cytokines IL-10 and TGF- $\beta 1$ as well as very low levels of IL-6 [8]. To our knowledge it is not known if SP contains IL-23.

\section{Conclusions}

The present study shows IL-23 mRNA to be expressed in the oviduct and endometrium in gilts $35-40 \mathrm{~h}$ after insemination. IL-23 immunolabelling was shown to be present in the subepithelial connective tissue of the endometrium and oviduct and in a low number of immune cells. Altogether, the results demonstrate a possible role for IL-23 in the immune response of reproductive tissue.

\section{Methods}

\section{Experimental design}


Animals and general management have been described earlier in a study on cytokine expression in the gilt oviduct [6]. Crossbred Landrace/Yorkshire gilts, about 8-9 months old, were brought from the University experimental herd (Swedish University of Agricultural Sciences) and euthanized (stunned by captive bolt followed by exsanguination). In brief, the gilts were inseminated with $100 \mathrm{~mL}$ of seminal plasma (SP, $n=4$ ), spermatozoa in extender (Beltsville thawing solution, BTS [17], SPZ, $n=4$ ) or extender (BTS) alone $(n=4)$. In four control gilts the disposable insemination catheter (Goldenpig ${ }^{\mathrm{TM}}$, IMV, L'Aigle, France) was inserted without any fluid being inseminated (control, $n=4$ ). The gilts were euthanized 35-40 $\mathrm{h}$ after insemination when tissue samples were collected, frozen in liquid nitrogen and stored at $-80^{\circ} \mathrm{C}$. Uterine samples were collected from the mesometrial side, 20-30 cm from the tip of the uterine horn. Oviductal samples were collected from the isthmus as well as from the infundibulum. The experimental study was approved by the Ethical Committee for Experimentation with Animals, Uppsala, Sweden (SLU.kv.Fe.2006.5.4.-15).

\section{Semen preparation and insemination}

The semen collection and preparation is detailed in [6]. In brief, semen was collected from four boars with proven fertility, then pooled and centrifuged. At every sampling the motility of the spermatozoa was examined. The SP was thereafter separated from the sperm layer, centrifuged twice to remove any remaining spermatozoa and stored at $-20^{\circ} \mathrm{C}$ until insemination.

Spermatozoa were isolated from semen using the single layer centrifugation technique (SLC, [14]). Briefly, a layer of semen extended with BTS was carefully layered on top of a colloid solution (Androcoll ${ }^{\mathrm{T}}-\mathrm{P} ; \mathrm{SLU}$ ) and centrifuged. The sperm pellet generated was transferred to a new tube containing BTS and washed by centrifugation. BTS was added to generate a dose of $100 \mathrm{~mL}$ containing $5 \times 10^{9}$ spermatozoa for insemination.

Gilts were inseminated once in their second or third oestrus at $15-20 \mathrm{~h}$ after the first signs of standing reflex (about 15-20 h before expected ovulation).

\section{Quantification of endometrial PMNs}

Quantification of PMNs in the endometrium was performed previously [7]. In brief, paraffin-embedded uterine samples were sectioned and stained with hematoxylin-eosin. Blind evaluation of slides was performed using a light microscope with a $\times 40$ objective. PMNs were counted in the surface epithelium and in the sub-epithelial connective tissue using an ocular micrometer, where the ocular field length and area obtained corresponded to $0.25 \mathrm{~mm}$ and $6.25 \times 10^{-2} \mathrm{~mm}^{2}$ of tissue, respectively. Ten random areas were chosen for evaluation in two different sections from each animal. Results are presented as the 
number of PMNs per ocular micrometer length (number of cells/OML) in the surface epithelium as well as per ocular micrometer area (number of cells/OMA) in the sub-epithelial connective tissue [7].

\section{RNA extraction}

Frozen oviductal tissues (isthmus and infundibulum) were cut in cross sections, resulting in a longitudinal length of 2-3 $\mathrm{mm}$ per piece. Endometrial samples were obtained by separating the endometrium from the myometrium, and cutting it into pieces of about $15-20 \mathrm{~mm}^{3}$. Tissues were homogenized using a micropestle; total RNA was extracted using $1 \mathrm{~mL}$ of TRIzol ${ }^{\circledR}$ reagent (Invitrogen Ltd., Paisley, UK) and purified using the RNeasy Mini kit (Qiagen, Crawley, UK) according to the manufacturer's instructions. RNA pellets were rehydrated in nuclease-free water (Qiagen, Crawley, UK). Total RNA content and purity was determined by $260 / 280 \mathrm{~nm}$ ratio using the NanoDrop ${ }^{\circledR}$ ND-1000 (Saveen \&Werner AB, Limhamn, Sweden). All samples used had ratios higher than 1.9. In addition, nine random samples from each experiment were checked for total RNA integrity using microcapillary electrophoresis (Agilent 2100 Bioanalyzer; Agilent Technologies, Waldbronn, Germany), as described for quality assurance of the extracted RNA [4].

\section{Quantitative Real-Time PCR}

Complementary DNA (cDNA) fragments were obtained using the iScript ${ }^{\mathrm{TM}}$ cDNA Synthesis Kit (Bio-Rad Laboratories, Hercules, CA) according to the manufacturer's instructions, where $1 \mu \mathrm{g}$ of total RNA was used for reverse transcription with both oligo(dT) and random hexamers as primers. Real-time PCR was performed using the Rotor-Gene 3000 (Corbett Life Science, Sydney, Australia) with the iQ SYBR Green Supermix (Bio-Rad Laboratories, Hercules, CA) according to the manufacturer's instructions. IL-23 primers (forward: 5'-TGT GGA TCT ACC AAG AGA AGA GG and reverse: 5'-AGG ACT GAC TGT TGT CCC TGA), were designed to amplify a $110 \mathrm{bp}$ cDNA fragment corresponding to nucleotides 168-277 of the pig IL-23 alpha subunit p19 mRNA sequence [GenBank Accession number NM_001130236]. Hypoxanthine phosphoribosyl-transferase (HPRT) primers (forward: 5'-GTG ATA GAT CCA TTC CTA TGA CTG TAG A and reverse: 5'-TGA GAG ATC ATC TCC ACC AAT TAC TT [GenBank Accession number U69731]; [22]) and cyclophilin A primers (forward: 5'-TGC TTT CAC AGA ATA ATT CCA GGA TTT A and reverse: 5'-GAC TTG CCA CCA GTG CCA TTA [GenBank Accession number AY266299]) were used to amplify cDNA fragments of 104 and $77 \mathrm{bp}$ respectively. The reaction volume was set to $25 \mu \mathrm{L}$ and the concentration of each primer was $0.2 \mu \mathrm{M} .1 \mu \mathrm{L}$ cDNA was added to each reaction. Duplicate samples were submitted to amplification as follows: $95^{\circ} \mathrm{C}$ for 2 min and 40 cycles of $95^{\circ} \mathrm{C}$ for $15 \mathrm{~s}$ and $60{ }^{\circ} \mathrm{C}$ for $1 \mathrm{~min}$. Nonspecific amplification was eliminated by generating dissociation curves. Amplification products were randomly analyzed by agarose gel electrophoresis. Reactions without template added were used as negative controls. Efficiency $(E)$ was calculated for each amplicon in a randomly chosen sample (infundibulum; SP treatment) giving efficiencies of 111\% (IL-23), 96\% (HPRT) and 95\% (cyclophilin A). 
For optimal comparison between runs the threshold was adjusted to obtain the same $C_{t}$ value for an interassay reference sample included in each run. IL-23 mRNA expression was normalized to HPRT and cyclophilin A mRNA expression by calculating the copy number for IL-23 in relation to the geometric mean value for the copy numbers for HPRT and cyclophilin A according to: $2^{\mathrm{Ct}}$ for IL-23 / geometric mean of $2^{\mathrm{Ct}}$ for HPRT and $2^{\mathrm{Ct}}$ for cyclophilin A

The normalized expression was used for statistical comparison between treatment groups. The results are presented as the inverted ratio (1/ratio) of the normalized expression [6].

\section{Immunohistochemistry}

Immunohistochemical analysis was performed on both oviductal (isthmus and infundibulum) and uterine samples. Transverse (oviduct) or longitudinal (uterus) sections of about $7 \mu \mathrm{m}$ were cut on a cryostat and placed on SuperFrost ${ }^{\circledR}$ Plus microscope slides (Menzel GmbH \& Co KG., Braunschweig, Germany). Sections were air-dried for about $30 \mathrm{~min}$ and rehydrated in phosphate-buffered saline (PBS) for $5 \mathrm{~min}$. Sections were blocked in $5 \%$ goat serum for $30 \mathrm{~min}$ and incubated overnight at $4^{\circ} \mathrm{C}$ with a rabbit anti-human IL-23 antibody (H-113; Santa Cruz Biotechnology Inc., Santa Cruz, CA) diluted to 0.2 $\mu \mathrm{g} / \mathrm{ml}$. The amino acid sequence showed $91.2 \%$ identity with the corresponding porcine protein sequence; sc-50303. Negative controls included sections incubated in the absence of the primary antibody and sections incubated with a control rabbit IgG (ChromPure Rabbit IgG [011-000-003], Jackson ImmunoResearch Laboratories Inc., West Grove, PA) diluted to a concentration exceeding that of the primary IL-23 antibody. After washing in PBS, IL-23-like immunolabelling was detected using the Vectastain ${ }^{\circledR}$ Elite ABC kit for Mouse IgG (PK-6102; Vector Laboratories Inc., Burlingame, CA). A biotinylated goat anti-rabbit IgG (BA-1000; Vector Laboratories Inc., Burlingame, CA) diluted 1/1000 was used instead of the biotinylated anti-mouse IgG as a negative control. Endogenous peroxidase activity was blocked by $0.3 \%$ hydrogen peroxidase in methanol. For visualization, 3 , 3'-diaminobenzidine tablets (D-5905; Sigma-Aldrich Inc., Saint Louis, MO) was used and sections were counterstained with Mayer's Hematoxylin. Slides were mounted in Kaiser's glycerol gelatine (109242; Merck KGaA, Darmstadt, Germany).

For semi-quantification of IL-23 immunolabelling, photographs were taken in a Nikon-FXA photomicroscope (Nikon Corporation, Tokyo, Japan) using the $\times 20$ objective with identical exposure settings for all photomicrographs taken. Photomicrographs were coded and examined by a group of three persons. The intensity of the immunolabelling of endometrium and endosalpinx was estimated according to a scoring system from $0-4$, where 0 corresponds to the intensity of the negative controls and 4 to very high intensity.

\section{Statistical analyses}


Quantitative real-time PCR results are presented as mean values \pm standard error of the mean (sem). Normalized mRNA expression data and IL-23-like immunolabelling intensity scores were statistically analyzed using the SAS statistical package (version 9.1.3, SAS Institute, Inc., 2002-2003, Cary, NC). A natural log transformation was applied to the normalized copy number to achieve the assumption required for analysis of variance. Differences in mean ratios were tested using analysis of variance (The Mixed Procedure). The statistical model included the fixed effect of treatment (SP, spermatozoa, extender and catheter only) and tissue (isthmus, infundibulum and endometrium). It also included analysis of the interaction between each group and tissue as well as the random effect of gilts nested within groups. The Bonferroni $t$-test was used to compare least-square mean values between experimental groups when an overall significance for the effect was found. A value of $p \leq 0.05$ was considered as statistically significant.

For statistical analysis of IL-23-like immunolabelling scores the NPAR1WAY procedure was used for standard analysis of variance. The Kruskal-Wallis test was used for one-way analysis of variance whereas differences in mean scores were analyzed using the Wilcoxon rank sum test for non-parametric data. A value of $p \leq 0.05$ was considered as statistically significant.

\section{Abbreviations}

BTS: Beltsville thawing solution; Cat: Catheter; E: Efficiency; GM-CSF: Granulocyte macrophage colonystimulating factor; HPRT: Hypoxanthine phosphoribosyl-transferase; IL-1 $\beta$ : Interleukin-1 $\beta$; IL-17: Interleukin 17; IL-6: Interleukin-6; IL-10: Interleukin-10; IL-23: Interleukin-23; OMA: Ocular micrometer area; OML: Ocular micrometer length; PMN: Polymorphonuclear neutrophilic granulocyte; sem: Standard error of the mean; SP: Seminal plasma; SPZ: Spermatozoa; Sub-CNT: Sub-epithelial connective tissue; TGF- $\beta 1$ : Transforming growth factor- $\beta 1$; Th17: T helper 17

\section{Declarations}

\section{Ethics approval and consent to participate}

The experimental study involving laboratory animals was approved by the Ethical Committee for Experimentation with Animals, Uppsala, Sweden (SLU.kv.Fe.2006.5.4.-15).

\section{Consent for publication}

Not applicable.

\section{Availability of data and materials}


The datasets used and/or analysed during the current study are available from the corresponding author on reasonable request.

\section{Competing interests}

The authors declare that they have no competing interests.

\section{Funding}

The authors wish to thank FORMAS, The Swedish Research Council 486 for Environment, Agricultural Sciences and Spatial Planning, for financial support. The funding covered purchase of the gilts, the costs for the housing of the gilts and the laboratory analyses. The wage costs for authors were covered by the department.

\section{Authors' contributions}

All authors planned and contributed to the preparation of the manuscript. JJ and AMD collected the samples. AS and JJ performed the analyses. AS is the main author. All authors read and approved the final manuscript.

\section{Acknowledgements}

The authors wish to thank Annika Rikberg for excellent technical assistance, Jane Morrell for kindly providing the sperm selection method and for linguistic corrections, Patrice Humblot for help with statistical analyses as well as Mikael Berg for providing access to laboratory facilities in the section of Virology at the Department of Biomedical Science and Veterinary Public Health at SLU in Uppsala.

\section{References}

1. Bischof RJ, Brandon MR, Lee C-S. Cellular immune responses in the pig uterus during pregnancy. J Reprod Immunol. 1995;29:161-178.

2. Cai JY, Li MJ. Interleukin 23 regulates the functions of human decidual immune cells during early pregnancy. Biochem Biophys Res Commun. 2016; 469:340-344. 
3. Cai JY, Li MJ, Huang QY, Fu XQ, Wu HM. Differences in cytokine expression and STAT3 activation between healthy controls and patients of unexplained recurrent spontaneous abortion (URSA) during early pregnancy. PLoS One. 2016;11:e0163252.

4. Copois V, Bibeau F, Bascoul-Mollevi C, Salvetat N, Chalbos P, Bareil C, et al. Impact of RNA degradation on gene expression profiles: assessment of different methods to reliablydetermine RNA quality. J Biotechnol. 2007;127:549-559.

5. Jiwakanon J, Persson E, Dalin A-M. The influence of pre- and post-ovulatory insemination and early pregnancy on the infiltration by cells of the immune system in the sow oviduct. Reprod. Dom. Anim. 2006;41:455-466.

6. Jiwakanon J, Berg M, Persson E, Fossum C, Dalin A-M. Cytokine expression in the gilt oviduct: effects of seminal plasma, spermatozoa and extender after insemination. Anim Reprod Sci. 2010;119:244257.

7. Jiwakanon J, Persson E, Berg M, Dalin A-M. Influence of seminal plasma, spermatozoa and semen extender on cytokine expression in the porcine endometrium after insemination. Anim Reprod Sci. 2011;123:210-220.

8. Jiwakanon J, Dalin A-M. Short communication: Concentration of TGF- $\beta 1$, IL-10 and IL-6 in boar seminal plasma and TGF- $\beta 1$ level in different fractions of ejaculates. Anim Reprod

Sci. 2012;131:194-198.

9. Kaeoket K, Persson E, Dalin A-M. The influence of pre- and post-ovulatory insemination on sperm to the zona pellucida, fertilisation rate and embryo development in sows. Anim Reprod Sci. 2002;71:239-248.

10. Kaeoket K, Persson E, Dalin A-M. Influence of pre-ovulatory insemination and early pregnancy on the infiltration by cells of the immune system in the sow endometrium. Anim Reprod Sci. 2003;75:55-71.

11. Karalyan Z, Voskanyan H, Ter-Pogossyan Z, Saroyan D, Karalova E. IL23/IL-17/G-CSF pathway is associated with granulocyte recruitment to the lung during African swine fever. Vet Immunol Immunopathol. 2016;179:58-62.

12. Matthijs A, Engel $B$, Woelders $\mathrm{H}$. Neutrophil recruitment and phagocytosis of boar spermatozoa after artificial insemination of sows, and the effects of inseminate volume, sperm dose and specific additives in the extender. Reprod. 2003;125:357-367.

13. Mills KHG. Induction, function and regulation of IL-17-producing T cells. Eur J Immunol. 2008;38:2636-2649. 
14. Morrell JM, Saravia F, Van Wienen M, Wallgren M, Rodriguez-Martinez H. Selection of boar spermtozoa using centrifugation on a glycidoxypropyltrimethoxy-silane coated silica colloid. J Reprod Dev. 2009;55:547-552.

15. O'Leary S, Jasper MJ, Warnes GM, Armstrong DT, Robertson SA. Seminal plasma regulates endometrial cytokine expression, leukocyte recruitment and embryo development in the pig. Reprod. 2004;128:237-247.

16. Oppmann B, Lesley R, Blom B, Timans JC, Xu Y, Hunte B, et al. Novel p19 protein engages IL12p40 to form a cytokine, IL-23, with biological activities similar as well as distinct from IL-12. Immun. 2000;13:715-725.

17. Pursel VG, Schulman L, Johnson LA. Effect of holding time on storage of boar spermatozoa at 5 degree celcius. J Anim Sci. 1973;37:785-789.

18. Robertson SA. Seminal fluid signaling in the female reproductive tract: lessons from rodents and pigs. J Anim Sci. 2007;85:E36-E44.

19. Rozeboom KJ, Troedsson MHT, Crabo BG. Characterization of uterine leukocyte infiltration in gilts after artificial insemination. J Reprod Fertil. 1998;114:195-199.

20. Taylor U, Zerbe H, Seyfert H-M, Rath D, Baulain U, Langner KFA, et al. Porcine spermatozoa inhibit post-breeding cytokine induction in uterine epithelial cells in vivo. Anim Reprod Sci. 2009;115:279289.

21. Uz YH, Murk W, Yetkin CE, Kayisli UA, Arici A. Expression and role of interleukin-23 in human endometrium throughout the menstrual cycle and early pregnancy. J Reprod Immunol. 2010;87:2127.

22. Zhu Y, Magnusson U, Fossum C, Berg M. Escherichia coli inoculation of porcine mammary glands affects local mRNA expression of Toll-like receptors and regulatory cytokines. Vet Immunol Immunopathol. 2008;125:182-189.

\section{Figures}




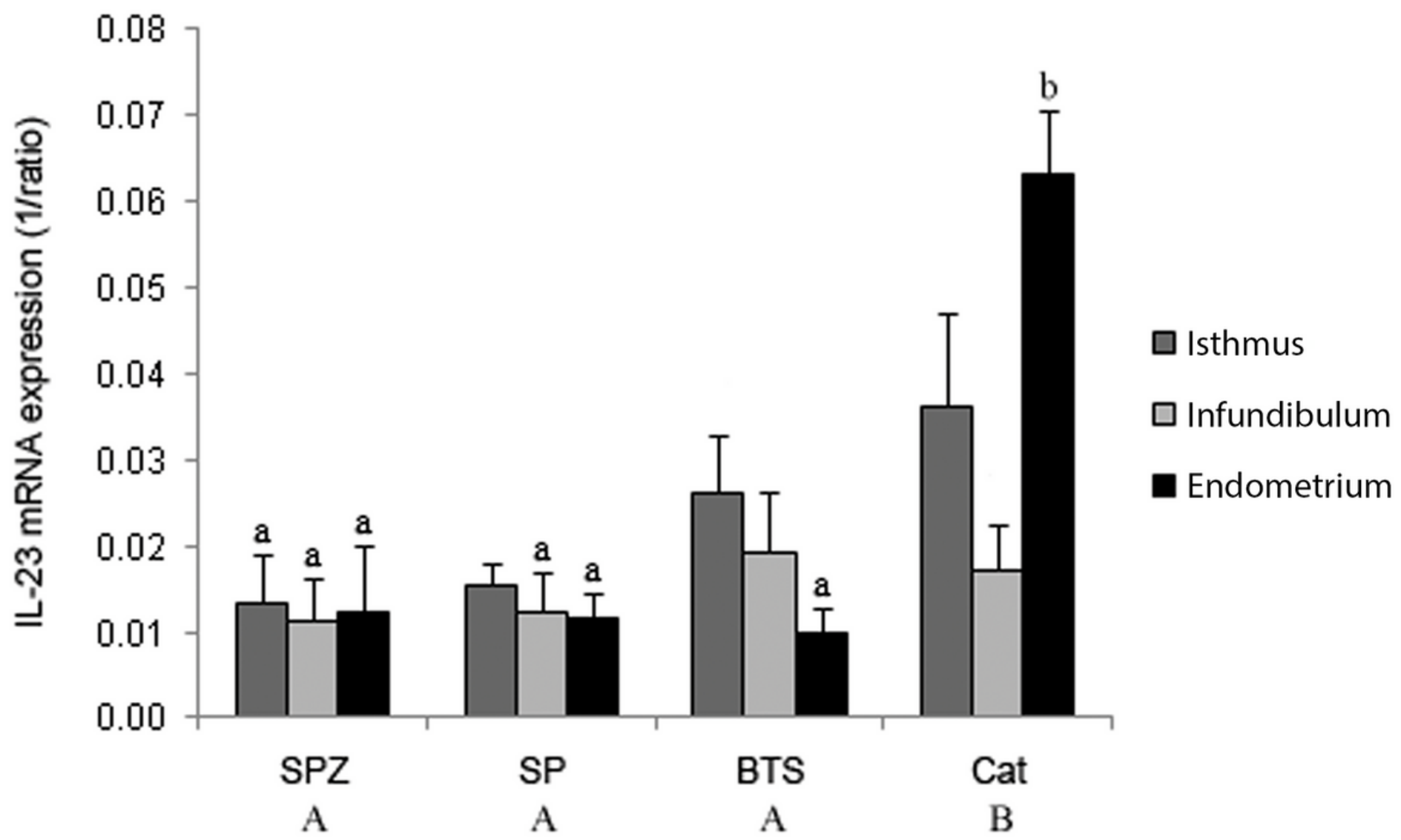

Figure 1

IL-23 mRNA expression in gilt oviduct and endometrium after insemination. IL-23 mRNA expression (mean 1/ratio \pm sem) in gilt oviduct (isthmus and infundibulum) and endometrium at $35-40 \mathrm{~h}$ after insemination with spermatozoa in BTS (SPZ), seminal plasma (SP), BTS and catheter-insertion only (Cat; $\mathrm{n}=4$ per treatment group). Bars or treatment groups marked by different letters show significant difference $(p \leq 0.05)$. BTS; Beltsville thawing solution. 


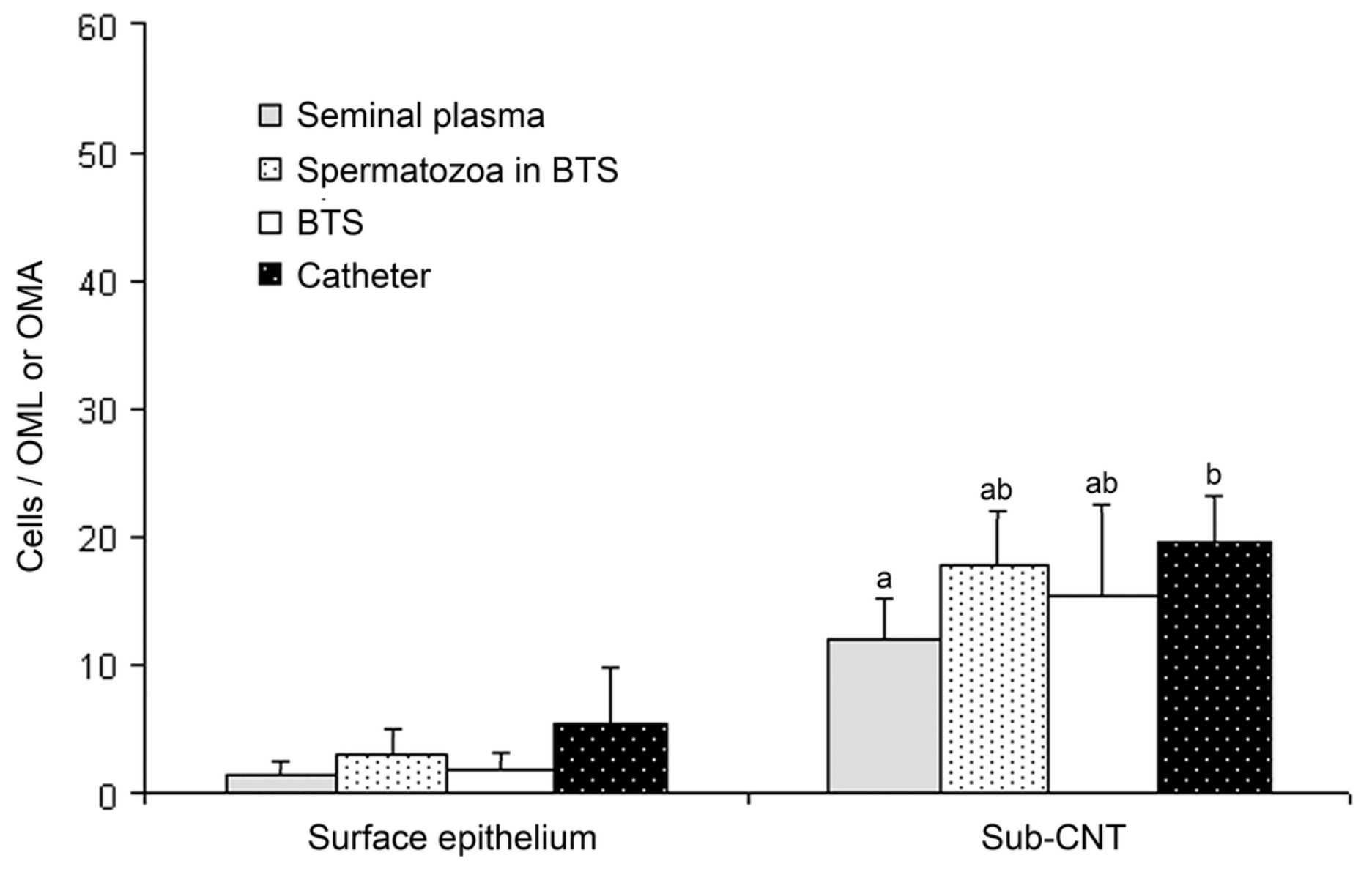

Figure 1

Neutrophil distribution in porcine endometrium after insemination. Neutrophil distribution (mean \pm SD) in the surface epithelium and sub-epithelial connective tissue (Sub-CNT) of the porcine endometrium at 35$40 \mathrm{~h}$ after insemination with seminal plasma (SP), spermatozoa in BTS, BTS or catheter only. Different letters on bars display significant difference ( $\leq \leq 0.05)$. BTS, Beltsville thawing solution; OML, one ocular micrometer length; OMA, one ocular micrometer area. 


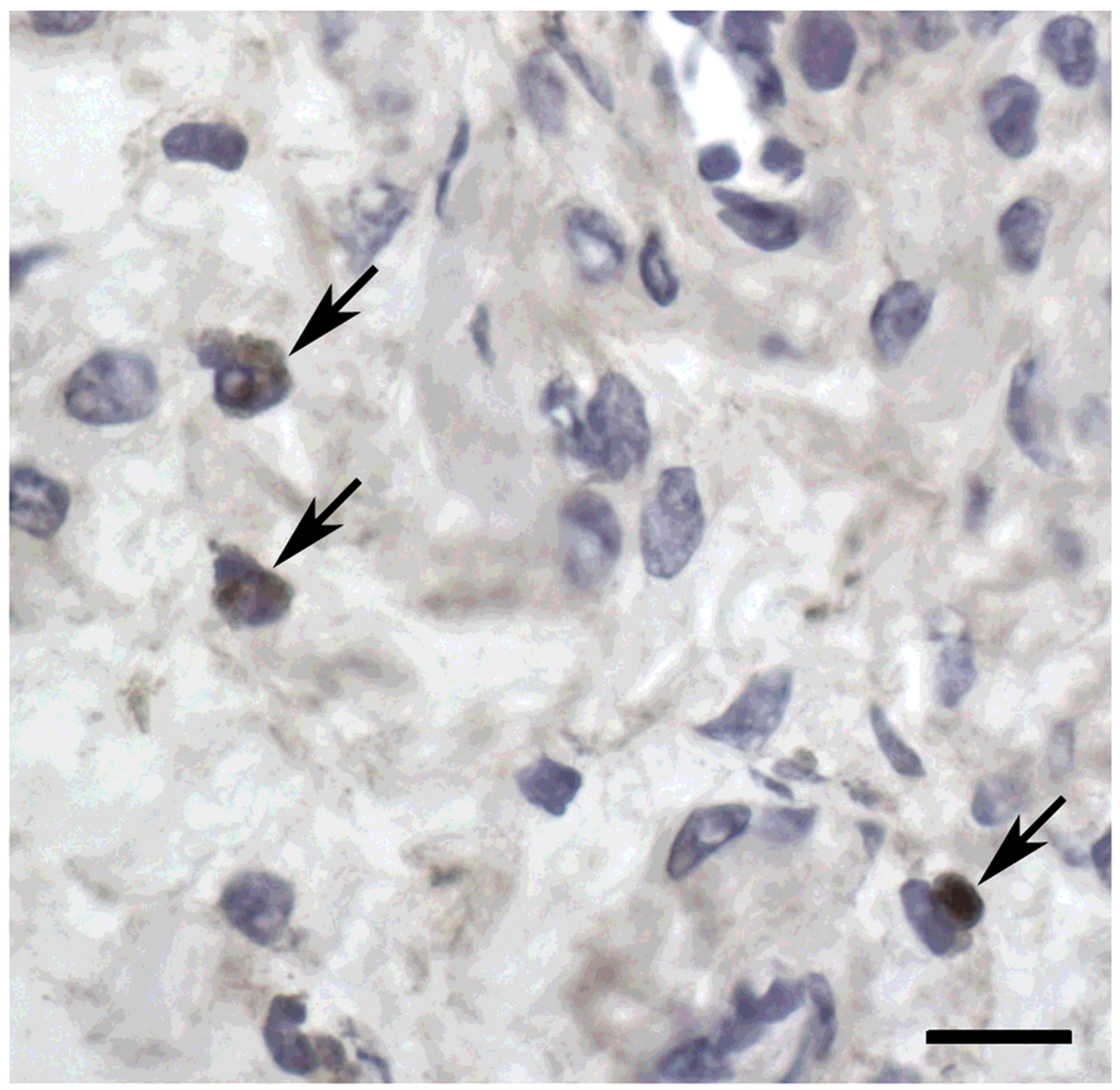

\section{Figure 1}

IL-23 immunolabelling of cells in gilt endometrium after insemination. Separate IL-23 immunolabelled cells (arrows) in the sub-epithelial connective tissue of gilt endometrium. Longitudinal section of the gilt endometrium at $35-40 \mathrm{~h}$ after catheter-insertion only. Picture is representative for all treatment groups. Bar $=10 \mu \mathrm{m}$. 

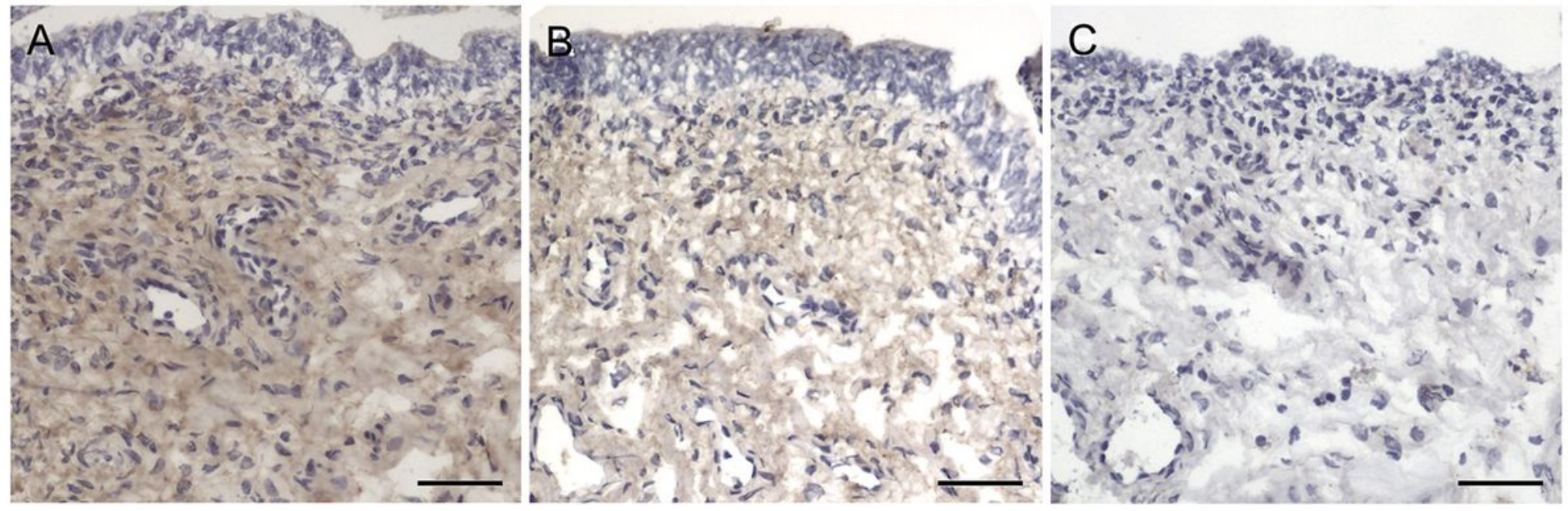

\section{Figure 1}

IL-23 immunolabelling in gilt endometrium at 35-40 $\mathrm{h}$ after insemination. IL-23 immunolabelling in gilt endometrium after insemination with seminal plasma (A) or BTS (Beltsville thawing solution; B). Longitudinal sections of surface epithelium and sub-epithelial connective tissue of gilt endometrium (AC). (C) Negative control (rabbit lgG) shows no obvious staining of the endometrium 35-40 h after insemination with BTS. Representative pictures from each group are presented. Bars $=50 \mu \mathrm{m}$.

\section{Supplementary Files}

This is a list of supplementary files associated with this preprint. Click to download.

- ARRIVEchecklist.docx

- SvenssonManuscriptrevised2.pdf 